\title{
Metallurgy: Energy and Environmental Issues
}

\author{
DEAN GREGUREK, ${ }^{1,5}$ ZHIWEI PENG,${ }^{2,6}$ PHILLIP J. MACKEY,, 3 \\ and CHRISTINE WENZL ${ }^{4,8}$
}

\begin{abstract}
1.-RHI AG, Technology Center Leoben, Magnesitstrasse 2, 8700 Leoben, Austria. 2.-School of Minerals Processing and Bioengineering, Central South University, Changsha, Hunan 410083, People's Republic of China. 3.-P.J. Mackey Technology Inc., Montreal, QC H9J 1P7, Canada. 4.-RHI AG, Wienerbergstrasse 9, 1100 Vienna, Austria. 5.-e-mail: dean.gregurek@rhi-ag.com. 6.-e-mail: zwpeng@csu.edu.cn. 7.—e-mail: pjmackey@hotmail.com. 8.—e-mail: christine. wenzl@rhi-ag.com
\end{abstract}

The current JOM topic "Metallurgy: Energy and Environmental Issues" gives the reader an update on current research work and developments in these fields. Today, it is not only sufficient to achieve high product quality, namely what comes out of a process, but also how this is achieved is important. The articles in the current topic cover a broad spectrum of considerations and efforts to make metallurgical processes "greener" and more sustainable.

Every metal producer aims for an economic and safe production process-hence, there is an economic incentive for energy saving and using cheap energy sources. Energy saving is always related with process optimization, which in turn requires a combination of excellent process knowledge and "out-of-the-box" thinking for implementation of new ideas and approaches. However, the environmental impact of process adaptations also must be considered, which is generally positive in the case of using less energy but could be negative in the case of cheap energy sources. Hence, numerous researchers worldwide are working to find alternative energy sources that are suitable for metallurgical processes and provide an economic as well as environmentally friendly solution, for example solar energy or biomass.

Because of the continuously stricter environmental regulations, metal producers are obligated to take the corresponding measures to reduce their environmental footprint and comply with the national and international laws. These measures may be cost intensive, leading to a shift of industrial production to countries with less strict regulations. However, the global aspect must be considered;

Dean Gregurek, Zhiwei Peng, and Phillip J. Mackey are the guest editors for the Pyrometallurgy Committee of the TMS Extraction and Processing Division and are coordinators of the topic Metallurgy: Energy and Environmental Issues in this issue. moving the problem and pollution to another location does not solve the problem. Therefore, new and economically attractive solutions must be found that make industrial processes "greener," especially in the so-called heavy industries including metal production. Another important factor is reducing landfill, which requires adaptations of existing processes and new processes for residue treatment, possibly with recovery of metal values and/or energy; the general aim is to avoid "wasting waste."

For process optimizations, it is vital to think "outof-the-box," to learn from other industries and from nature, and to use multidisciplinary synergies. The editors hope that the readers will find some new ideas in the articles presented under the topic "Metallurgy: Energy and Environmental Issues" and can use them as a basis for their own developments and process improvements. To download any of the papers, follow the URL http://link.springer. com/journal/11837/67/5/page/1 to the Table of Contents page for the May 2015 issue (vol. 67, no. 5).

- P. Coursol, P.J. Mackey, J.P.T Kapusta, and N. Cardona Valencia: "Energy Consumption in Copper Smelting: A New Asian Horse in the Race" Tremendous improvements were achieved regarding improvements in energy consumption over the last decades. Although in the past mainly Europe and the Americas were the main drivers of technology development, today Asia's role in innovation is continuously increasing. The article describes new Asian developments for making metallurgical processes more environmentally friendly and explains the benefits of using the new bottom-blowing technology for copper production.

- Biljana Maluckov: "Bioassisted Phytomining of Gold"

This article makes a thought-provoking case for using natural processes in metallurgy, namely 
using microorganisms and plants for selective recovery of metals from soils with high metal content. The described method of bioassisted phytomining is a good example of residue treatment and winning metals from sources that might not be attractive for conventional metal-production routes.

- W.J. Duan, Q.B. Yu, Z.L. Zuo, Q. Qin, J.X. Liu, and P. Li: "Thermodynamic Analysis of BlastFurnace Slag Waste Heat Recovery System Integrated with Coal Gasification"

Slags are a common by-product of metallurgical processes and are a valuable material-consideringnot only possible metal values that can be recovered but also their contained heat energy. The article describes how to recover the energy from blast furnace slags, using a combination of existing technologies as a basis and exploiting the possibilities of thermodynamics. The described method of energy recovery by using a slag's waste heat is an interesting and promising example for thermal recycling.

- J. Matousek: "Oxygen in Molten Iron: Deoxidation with Silicon and Aluminum"

To improve a process and its environmental footprint as well as energy consumption, it is vital first of all to understand fully the process and influencing parameters-only then, the right levers can be pulled for obtaining not only a highquality product but also an economic and environmentally sound process. The article presents an overview and comprehensive summary of oxygen in steel and methods for deoxidation, including thermodynamic considerations.

- A. Alaoui, K. EL Kacemi, K. EL Ass, S. Kitane, and S. El Bouzidi: "Box-Behnken Design Application to Study Leaching of Pyrolusite from Manganese Mining Residue Using Olive Mill Wastewater as Reductant"

This paper describes the use of the residue from one industry as a valuable process component in another. A new leaching process is suggested, using wastewater as leaching agent for another residue, namely mine tailings, including an evaluation using statistical methods (Box-Behnken experimental design).

- N. Tzouganatos, M. Dell'Amico, C. Wieckert, J. Hinkley, and A. Steinfeld: "On the Development of a Zinc Vapor Condensation Process for the Solar Carbothermal Reduction of Zinc Oxide" Some metallurgical processes have been used for decades and even centuries-however, this does not mean that they could not be improved. The article describes a new technology for condensation of $\mathrm{Zn}$ vapor, namely for producing liquid zinc from the gas products evolving from the solar carbothermal reduction of zinc oxide.
- C. Zhang, W. Cao, J. Zhan, F. Ding, and J.-Y. Hwang: "Extraction Equilibrium of $\mathrm{Mn}^{2+}, \mathrm{Ca}^{2+}$, and $\mathrm{Mg}^{2+}$ from Chloride Solutions by Di(2-ethylhexyl)Phosphoric Acid Dissolved in Kerosene" Hydrometallurgical processes are always associated with a certain amount of liquids that have to be treated in a suitable way to recover potential metal values and avoid negative environmental impact. This article studies an environmentally friendly extraction method for $\mathrm{Mn}, \mathrm{Ca}$, and $\mathrm{Mg}$ ions from manganese leaching solutions.

- J. Zhan, Z.-J. Wang, C.-F. Zhang, J.-Y. Hwang, and C.-P. Xia: "Separation and Extraction of Bismuth and from Roasted Low-Grade Bismuthinite and Pyrolusite: Thermodynamic Analysis and Sulfur Fixing"

Depending on metal prices, it may become economically interesting also to process low-grade "problematic" materials. These materials generally have a low content of the main metal and a high amount of accompanying metals, which may complicate the process and main metal recovery. The current article presents a new environmentally friendly technology with high $\mathrm{Bi}$ metal recovery from low-grade raw material and coproduction of other valuables, including a thermodynamic study of the behavior of the main metal and accompanying metals.

- C. Lin, H. Zhandong, Y. Tianzu, L. Weifeng, Z. Duchao, Z. Li, B. Shu, and B. Wanda: "A Comparison Study of Oxygen-Rich Side Blow Furnace and Oxygen-Rich Bottom Blow Furnace for Liquid High-Lead Slag Reduction"

Many metallurgical slags still contain a high amount of metals that are worthy to be recovered. Additionally, composition limits for landfills must be fulfilled. A proven technology for such treatment is slag reduction. The article describes a reduction process for slags with high lead content, comparing and discussing new furnace types, namely oxygen-rich side blow furnace (OSBF) and oxygen-rich bottom blow furnace (OBBF), for carrying out the slag reduction process and achieving minimum final lead content in the slag.

- P. Jang, H. Li, W. Kim, Z. Wang, and G. Liu: "Preparation of Al-La Master Alloy by Thermite Reduction in NaF-NaCl-KCl Molten Salts"

The processes using molten salt must deal with complex and corrosive electrolyte systems and must be well understood to achieve the desired process performance and outcome. The article studies the solubility of $\mathrm{La}_{2} \mathrm{O}_{3}$ in $\mathrm{NaF}$ $\mathrm{NaCl}-\mathrm{KCl}$ molten salt and how the electrolyte composition, namely molten salt, influences the final alloy. 